\title{
Métodos de aplicação de nitrogênio na cultura do milho em solo de cerrado
}

\author{
Evandro Marcos Biesdorf ${ }^{1}$, Elivelton Maciel Biesdorf ${ }^{2}$, Matheus Ferreira França Teixeira1, \\ Otto Herbert Dietrich ${ }^{1}$, Leonardo Duarte Pimentel ${ }^{1}$, Charles de Araujo ${ }^{2}$
}

\author{
${ }^{1}$ Universidade Federal de Viçosa - UFV, Viçosa, Minas Gerais, Brasil. E-mail: evandromarcospva@ hotmail.com, \\ teixeiramff@gmail.com, otto.dietrich@ifes.edu.br, leonardopimentelagro@gmail.com \\ ${ }^{2}$ Instituto Federal do Mato Grosso - IFMT, Campus São Vicente, Campo Verde, Mato Grosso, Brasil. E-mail: \\ elivelton.biesdorf@agronomo.eng.br, charles.araujo@svc.ifmt.edu.br
}

Recebido: 07/12/2015; Aceito: 02/04/2015.

\section{RESUMO}

$\mathrm{O}$ nitrogênio $(\mathrm{N})$ é o nutriente mais limitante à produtividade do milho, sendo requerido em grandes quantidades para suprir a demanda da cultura. Além disso, o $\mathrm{N}$ aplicado via fertilizante mineral é muito susceptível a perdas por volatilização e/ou lixiviação, o que sugere a necessidade de estudos sobre métodos de aplicação visando otimizar o uso deste insumo. Objetivou-se com este estudo avaliar os efeitos de métodos de aplicação de N na cultura do milho nas condições do Cerrado Mato-grossense. Foram testadas duas formas de aplicação do N, na forma de ureia: aplicação a lanço em área total e incorporação ao solo na linha de plantio as quais foram parceladas em duas aplicações (semeadura e estádio vegetativo V6). O delineamento experimental utilizado foi o de blocos casualizados com três tratamentos e sete repetições. No estádio do pleno florescimento masculino assim como em R2, R3 e R6 observou-se, entre os tratamentos, diferença na altura das plantas, diâmetro de colmo, peso de matéria fresca e seca da parte aérea. Por outro lado, a leitura do teor de clorofila na folha não foi alterada pelo método de aplicação de N. A maior produtividade e peso de matéria seca de grãos foi obtida com a incorporação do $\mathrm{N}$ ao solo. Os resultados obtidos neste estudo sugerem que a aplicação de $\mathrm{N}$ de forma incorporada ao solo é a melhor estratégia para a obtenção de altas produtividades de grãos de milho para as condições do estado do Mato Grosso.

Palavras-chave: Adubação nitrogenada; Incorporação ao solo; Produtividade de milho.

\section{Nitrogen application methods on the maize crop in cerrado soil}

\begin{abstract}
The nitrogen $(\mathrm{N})$ is the big limiter for maize yields, which is required in large amounts to make up the crop request. In addition, the $\mathrm{N}$ applied by mineral fertilizer is more susceptible to losses by evaporation and/or leaching, showing the necessity for studies about application methods to optimize the use of that nutrient. The objective of this study was to evaluate the effects of $\mathrm{N}$ application methods on maize crop in the Mato Grosso state of Brazil in the biome Cerrado. Two N application methods, using urea: application by throwing in total area and incorporation in the planting line, which were divided in two applications (planting and V6 stage) were tested. The experimental design was a randomized complete block with three treatments and seven repetitions. At the tasseling stage, as well as in R2, R3 and R6, was observed among treatments, differences for the variables plant height, stalk diameter, weight fresh and dry of the shoots. However, the chlorophyll levels in the leaf were not changed by the $\mathrm{N}$ application method. The highest yield and dry weight of grain was obtained with the $\mathrm{N}$ incorporation in the line planting. The results of this study suggesting that the $\mathrm{N}$ incorporated into the soil, in the line planting, is the best strategy for maize yield increase in the Mato Grosso State, Brazil.
\end{abstract}

Key words: Nitrogen fertilization; Soil incorporation; Maize yield. 


\section{Introdução}

O milho (Zea mays L.) é o principal cereal produzido no Brasil, cuja safra 2014/2015 atingiu 84 milhões de toneladas em aproximadamente 15 milhões de hectares (CONAB, 2015). Produtividades superiores a $16 \mathrm{Mg} \mathrm{ha}^{-1}$ já foram obtidas em concursos de produtividade de milho conduzidos por órgãos de assistência técnica e empresas produtoras de semente (EMBRAPA, 2006). No entanto, a produtividade média nacional é baixa, aproximando-se de $5.382 \mathrm{~kg} \mathrm{ha}^{-1}$ (CONAB, 2015). Essa produtividade baixa sugere que os sistemas de produção de milho podem ser melhorados, especialmente quanto à nutrição mineral.

A cultura do milho é altamente exigente em nitrogênio, o que torna esse nutriente o mais limitante à produção quando não suprido de forma adequada durante os estádios iniciais de desenvolvimento (COSTA et al., 2012). Dados na literatura registram que cerca de 70 a $90 \%$ dos ensaios de adubação de milho realizados no Brasil em condições de campo apresentaram respostas crescentes à aplicação de nitrogênio (N) (COELHO, 2008).

A fonte de $\mathrm{N}$ mais utilizada na agricultura brasileira é a ureia, seguida do sulfato de amônio. A ureia tem como vantagem a elevada concentração de $\mathrm{N}( \pm 45 \%)$ o que otimiza custos com transporte e aplicação. Por outro lado, apresenta grande potencial de perda de NH3 por volatilização (FONTOURA; BAYER, 2010). Logo, o fornecimento de $\mathrm{N}$ utilizando fontes minerais, especialmente a ureia, requer técnicas de manejo da aplicação aperfeiçoadas para evitar perdas e, ou, otimizar os custos por unidade de $\mathrm{N}$ aplicado ao solo, sobretudo nas condições edafoclimáticas das áreas cultivadas do Cerrado Mato-Grossense, maior produtor de milho nacional.

A estratégia mais utilizada para minimizar essas perdas é o parcelamento da adubação nitrogenada incorporando-se ao solo, permitindo a sincronização entre as aplicações e o período de alta demanda de nutrientes, reduzindo-se assim perdas por volatilização (CANTARELLA; MARCELINO, 2008). Neste caso, minimiza-se as perdas de insumos, porém aumenta-se o custo com operações mecanizadas, não havendo, portanto, uma solução clara para o problema. Apesar disso, existe uma tendência entre os produtores matogrossenses de se fazer adubações nitrogenadas a lanço (sem incorporação), com intuito de reduzir os custos com aplicação e otimizar o uso de máquinas. Entretanto, a eficiência dos fertilizantes nitrogenados tem sido menor quando esses são aplicados na superfície, sem a imediata incorporação ao solo, sobretudo pelo processo de volatilização (SILVA et al., 2005).

A necessidade no manejo do $\mathrm{N}$, principalmente quando utilizada a ureia, é aumentar a quantidade absorvida pelas plantas e diminuir, ao mesmo tempo, as perdas ocorridas (SILVA et al., 2005). Assim, independentemente do método de aplicação do $\mathrm{N}$ no solo (incorporado ou a lanço), o desejável é que o $\mathrm{N}$ seja dissolvido o mais rápido possível (FERRARA et al., 2014). Embora muitos trabalhos de pesquisa tenham sido realizados nos últimos anos com a cultura do milho, muitas dúvidas existem sobre como e quando realizar a adubação nitrogenada (SOUZA et al., 2011). Portanto, a realização de estudos que avaliem métodos de aplicação de $\mathrm{N}$ se fazem necessários para melhor aproveitamento desse recurso e ao mesmo tempo otimizar a relação custo benefício do método de aplicação (SOUZA et al., 2011).

Nesse contexto, objetivou-se com este estudo avaliar os efeitos de métodos de aplicação de $\mathrm{N}$ na cultura do milho nas condições do Cerrado Mato-Grossense.

\section{Material e Métodos}

A pesquisa foi realizada na área experimental do Instituto Federal de Educação, Ciência e Tecnologia do Estado de Mato Grosso (IFMT), Campus de São Vicente, localizado no município de Santo Antônio do

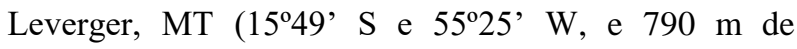
altitude), na safra 2011/2012. O solo foi classificado como Latossolo Vermelho distrófico (LVd) de textura média, com relevo suave ondulado a ondulado, em ambiente de cerrado. O clima da região é do tipo Aw pela classificação de Köeppen, tropical chuvoso com estação seca no inverno e chuvosa no outono, com precipitação anual média de $2000 \mathrm{~mm}$ e temperatura média mensal de $22,2{ }^{\circ} \mathrm{C}$ (OLIVEIRA et al., 2004).

$\mathrm{O}$ delineamento utilizado foi $\mathrm{o}$ de blocos casualizados (DBC) com três tratamentos e sete repetições. Cada unidade experimental foi constituída por quatro linhas de $5,0 \mathrm{~m}$ de comprimento, espaçadas entre si por 0,45 $\mathrm{m}$ (área total de $9 \mathrm{~m}^{2}$ ) com 3,33 plantas por metro. Entre blocos o espaçamento foi de 1,5 m. Para eliminar o efeito de bordadura, foi considerada como área útil as duas fileiras centrais, desprezando-se $0,45 \mathrm{~m}$ das extremidades laterais e $0,45 \mathrm{~m}$ das extremidades de cada linha de plantio.

Os tratamentos foram constituídos de três modos de aplicação de nitrogênio (N): i) ausência de aplicação de $\mathrm{N}$ (controle); ii) aplicação a lanço em área total (tanto no plantio quanto na cobertura) e; iii) aplicação localizada na linha de plantio e incorporada ao solo (tanto no plantio quanto na cobertura). A dosagem de $\mathrm{N}$ necessária à cultura foi parcelada em duas etapas (semeadura e estádio V6 - seis folhas completamente desenvolvidas). A incorporação do $\mathrm{N}$ ao solo se deu através de sulco paralelo à linha de semeadura do milho, $5 \mathrm{~cm}$ ao lado da linha de semeadura e a $10 \mathrm{~cm}$ de profundidade. $\mathrm{Na}$ aplicação a lanço, o $\mathrm{N}$ foi aplicado manualmente em área total. 
A área experimental foi de $216 \mathrm{~m}^{2} \mathrm{e}$ o solo da área apresentava as seguintes características na camada de 0 $-0,20 \mathrm{~m}: \mathrm{P}\left(\right.$ Extrator Mehlich $\left.^{-1}\right)=50,5 \mathrm{mg} \mathrm{dm}^{-3}$; Matéria orgânica $=27 \mathrm{~g} \mathrm{dm}^{-3} ; \mathrm{pH}\left(\mathrm{CaCl}_{2}\right)=5,5 ; \mathrm{K}, \mathrm{Ca}$, $\mathrm{Mg}, \mathrm{Al} \mathrm{e} \mathrm{H}+\mathrm{Al}=2,9 ; 29 ; 12 ; 0$ e $41 \mathrm{mmol}_{\mathrm{c}} \mathrm{dm}^{-3}$, respectivamente e $\mathrm{V} \%=56 \%$.

Os dados meteorológicos foram monitorados ao longo da condução do experimento. A temperatura média foi de $24,8{ }^{\circ} \mathrm{C}$ enquanto que a precipitação total durante o período do experimento foi de $1795 \mathrm{~mm}$. Os meses de maiores índices pluviométricos foram novembro e dezembro os quais apresentaram valores de $275,3 \mathrm{~mm}$ e $211,3 \mathrm{~mm}$, respectivamente (Figura 1). A adubação utilizada foi baseada na recomendação para a cultura (ALVES et al., 1999), variando apenas o modo de aplicação do $\mathrm{N}$, conforme os tratamentos. Foi realizado, anteriormente à implantação do experimento, gradagem superficial utilizando-se grade niveladora BALDAN NV ${ }^{\circledR}$, com diâmetro de eixo de 1.1/4" e profundidade de trabalho de $15 \mathrm{~cm}$ para fins de destorroamento e limpeza.

A adubação de semeadura foi realizada com a aplicação de $20 \mathrm{~kg} \mathrm{ha}^{-1}$ de N, $120 \mathrm{~kg} \mathrm{ha}^{-1}$ de $\mathrm{P}_{2} \mathrm{O}_{5}$ e 100 $\mathrm{kg} \mathrm{ha}^{-1}$ de $\mathrm{K}_{2} \mathrm{O}$. Em cobertura, no estádio V6, foram aplicados $140 \mathrm{~kg} \mathrm{ha}^{-1}$ de $\mathrm{N}$. Não foram realizadas irrigações suplementares. Utilizou-se como fonte de nitrogênio (N) a ureia, de $\mathrm{P}$ o superfosfato simples e de $\mathrm{K}$ o cloreto de potássio, estes últimos aplicados todos na semeadura, não variando entre os tratamentos.

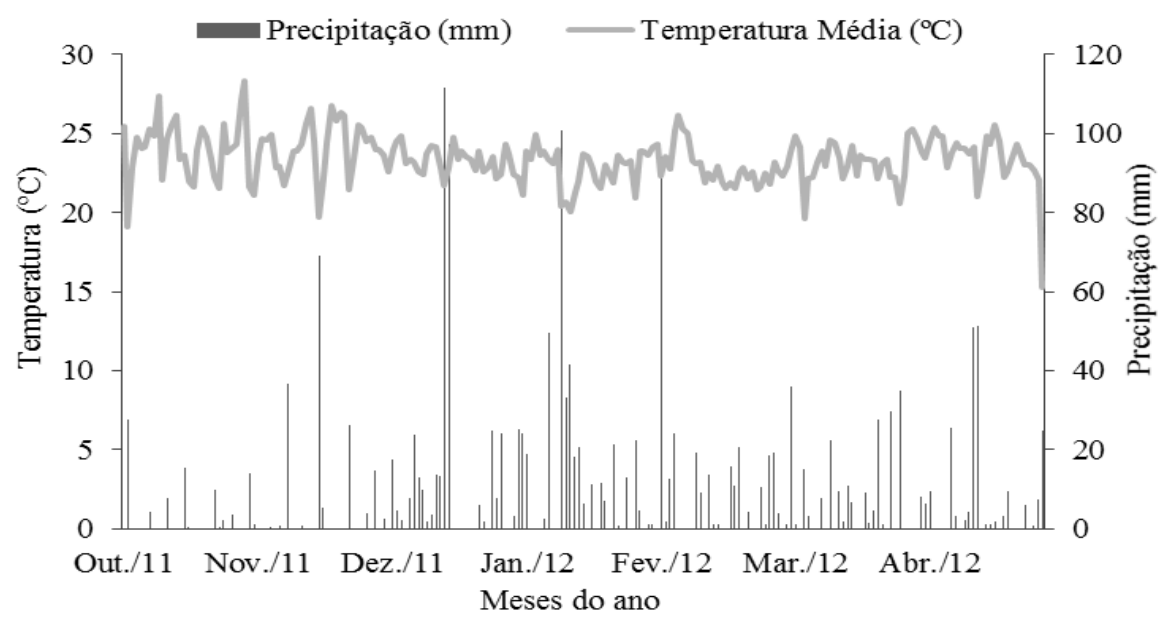

Figura 1. Precipitação pluviométrica ocorrida no período de novembro de 2011 a abril de 2012 na Fazenda experimental de São Vicente da Serra, IFMT - Campus São Vicente, Santo Antônio de Leverger, 2012. Fonte: Elaboração dos autores.

Foram utilizadas sementes de milho de ciclo precoce, híbrido simples 30F35H Pioneer ${ }^{\circledR}$. O controle de pragas foi realizado somente para Spodoptera frugiperda e Helicoverpa zea quando atingiram o nível de dano econômico da cultura, sendo realizado com óleo de NIN, aplicado na dose de 0,5\%, em pulverizações com bomba costal, totalizando três aplicações, sendo a primeira realizada aos 45 dias após a semeadura e a segunda aos 85 dias após a semeadura.

No estádio do pleno florescimento masculino $(\mathrm{Vt}) \mathrm{e}$ em R2 (Grão bolha d'água), R3 (Grão leitoso) e R6 (Maturidade fisiológica) foram avaliadas as seguintes variáveis nas plantas localizadas em $1,0 \mathrm{~m}$ da parcela útil: altura de planta (AP) (m), diâmetro de colmo (DC) $(\mathrm{cm})$, matéria fresca da parte aérea (MFPA) $\left(\mathrm{kg} \mathrm{pl}^{-1}\right)$, peso da matéria seca da parte aérea (MSPA) $\left(\mathrm{kg} \mathrm{pl}^{-1}\right) \mathrm{e}$ leitura do teor de nitrogênio da folha (unidades SPAD). Em R6 foram avaliados a produtividade de grãos ( $\mathrm{kg}$ ha${ }^{1}$ ) e peso da massa seca de grãos (PMSG) (g). A colheita foi realizada manualmente nas plantas localizadas em $1,0 \mathrm{~m}$ da parcela útil na maturidade fisiológica da cultura
(CARVALHO et al., 2014), seguida de debulha das espigas. A produtividade de grãos $\left(\mathrm{kg} \mathrm{ha}^{-1}\right)$ foi obtida com a pesagem dos grãos obtidos da debulha corrigindo-se a umidade dos grãos para $13 \%$ b.u. e convertido para $\mathrm{kg} \mathrm{ha}^{-1}$. Para a quantificação do peso de matéria fresca (MFPA) e seca da parte aérea (MSPA) assim como para o peso de matéria seca de grãos (PMSG) procedeu-se a secagem do material a $65^{\circ} \mathrm{C}$ por 72 horas (ou até peso constante), seguida da pesagem em balança digital com precisão de duas casas decimais. Para a leitura dos índices de Clorofila na folha foi utilizado o Clorofilômetro da MINOLTA SPAD-502 (Konica Minolta Sensing Americas Inc., Ramsey, MI, EUA) nas plantas contidas em $1 \mathrm{~m}$ linear na parcela útil. As leituras - duas por folha - foram feitas a dois centímetros da margem da folha e, a partir da base, entre a metade e dois terços do comprimento da folha (ARGENTA et al., 2001).

Os dados foram submetidos à análise de variância e as médias foram comparadas pelo teste de Tukey, ao nível de $5 \%$ de probabilidade. Foi realizado teste de 
correlação de Pearson $\left(\mathrm{R}^{2}\right)$ entre produtividade de grãos $\left(\mathrm{kg} \mathrm{ha}^{-1}\right)$ e peso da matéria seca de grãos (PMSG) (g).

\section{Resultados e Discussão}

A aplicação de $\mathrm{N}$ teve influência significativa para altura de em todos os estádios avaliados (Tabela 1). Ainda para a variável altura de planta (AP), entre os modos de aplicação de $\mathrm{N}$, não houve diferença estatística $(\mathrm{P}<0,05)$ nos estádios de pleno florescimento masculino, R3 e R6. Contudo, nesses estádios houve uma superioridade, em termos percentuais, de $3 \%$ para o método de aplicação incorporando-se $\mathrm{N}$ ao solo. Por outro lado, os resultados encontrados para altura de planta em R2 demonstram a intensa absorção de $\mathrm{N}$ neste estádio, haja vista a diferença significativa observada entre os métodos de aplicação. Com efeito, apesar do apontamento feito por Silva et al. (2005) em que demonstra que a altura de planta em milho é uma característica de alta herdabilidade genética e menos dependentes do meio, este resultado observado em R2 sugere que a aplicação de $\mathrm{N}$ incorporando-se ao solo pode ter reduzido as perdas de $\mathrm{N}$ por volatilização, proporcionando uma quantidade superior do $\mathrm{N}$ à planta de milho.

De acordo com Büll (1993) e Varvel et al. (1997), uma planta bem nutrida em $\mathrm{N}$ apresenta maior crescimento da área foliar e do sistema radicular, pois este nutriente influencia a divisão e expansão celular e fotossíntese, o que leva ao aumento da altura de plantas e, consequentemente, da altura de espiga. Resultados semelhantes foram obtidos por Santos e Pereira (1994) entre altura de plantas e espigas, trabalhando com milho no SPD e Tozetti et al. (2004) quando de sua avaliação em progênies de milho na presença e ausência de adubo, verificaram que a adubação afeta diretamente a altura de plantas.

Nas análises de diâmetro de colmo (DC), observouse melhores resultados com o fornecimento de $\mathrm{N}$, haja vista $\mathrm{o}$ fato que o tratamento controle (sem $\mathrm{N}$ ) apresentou o pior resultado nos estádios R2 e R6, entretanto, no estádio do pleno florescimento masculino e em R3, os valores apresentados pelo tratamento controle não diferiram estatisticamente da aplicação de $\mathrm{N}$ a lanço.

Tabela 1. Altura de planta (AP), diâmetro de colmo (DC), peso de matéria fresca da parte aérea (MFPA), peso de matéria seca da parte aérea (MSPA) e leitura SPAD (unidades SPAD) das plantas de milho no estádio do pleno florescimento masculino (Vt), R2 (Grão bolha d'água), R3 (Grão leitoso) e R6 (Maturidade fisiológica) em função do modo de aplicação de $\mathrm{N}$ na forma de ureia.

\begin{tabular}{|c|c|c|c|c|}
\hline \multirow{2}{*}{ Modo de aplicação } & \multicolumn{4}{|c|}{ Estádio fenológico do milho } \\
\hline & $\mathrm{Vt}$ & $\mathrm{R} 2$ & R3 & R6 \\
\hline & \multicolumn{4}{|c|}{$\mathrm{AP}\left(\mathrm{m} \mathrm{pl}^{-1}\right)$} \\
\hline Controle & $1,83 \mathrm{~b}$ & $2,11 \mathrm{c}$ & $2,18 \mathrm{~b}$ & $2,19 \mathrm{~b}$ \\
\hline $\mathrm{N}$ incorporado ao solo & $2,02 \mathrm{a}$ & $2,37 \mathrm{a}$ & $2,37 \mathrm{a}$ & $2,36 \mathrm{a}$ \\
\hline $\mathrm{N}$ a lanço & $2,00 \mathrm{a}$ & $2,25 \mathrm{~b}$ & $2,29 \mathrm{a}$ & $2,29 \mathrm{a}$ \\
\hline \multirow[t]{2}{*}{ C.V. (\%) } & 4,02 & 2,32 & 2,39 & 2,17 \\
\hline & \multicolumn{4}{|c|}{$\mathrm{DC}\left(\mathrm{mm} \mathrm{pl}^{-1}\right)$} \\
\hline Controle & $21,1 \mathrm{~b}$ & $20,3 c$ & $18,9 \mathrm{~b}$ & $18,0 \mathrm{c}$ \\
\hline $\mathrm{N}$ incorporado ao solo & 26,6 a & $24,9 \mathrm{a}$ & $23,7 \mathrm{a}$ & $22,0 \mathrm{a}$ \\
\hline $\mathrm{N}$ a lanço & $24,2 \mathrm{~b}$ & $22,7 \mathrm{a}$ & $21,4 \mathrm{~b}$ & $20,2 b$ \\
\hline \multirow[t]{2}{*}{ C.V. (\%) } & 7,03 & 5,41 & 7,48 & 5,32 \\
\hline & \multicolumn{4}{|c|}{$\operatorname{MFPA}\left(\mathrm{kg} \mathrm{pl}^{-1}\right)$} \\
\hline Controle & $0,61 \mathrm{~b}$ & $0,53 \mathrm{~b}$ & $0,77 \mathrm{~b}$ & $0,35 \mathrm{~b}$ \\
\hline $\mathrm{N}$ incorporado ao solo & $0,92 \mathrm{a}$ & $0,90 \mathrm{a}$ & $1,14 \mathrm{a}$ & $0,65 \mathrm{a}$ \\
\hline $\mathrm{N}$ a lanço & $0,73 \mathrm{~b}$ & $0,78 \mathrm{a}$ & $0,91 \mathrm{~b}$ & $0,47 \mathrm{~b}$ \\
\hline \multirow[t]{2}{*}{ C.V. (\%) } & 14,48 & 15,83 & 12,27 & 22,9 \\
\hline & \multicolumn{4}{|c|}{$\operatorname{MSPA}\left(\mathrm{kg} \mathrm{pl}^{-1}\right)$} \\
\hline Controle & $0,13 \mathrm{~b}$ & $0,13 \mathrm{~b}$ & $0,16 \mathrm{~b}$ & $0,10 \mathrm{~b}$ \\
\hline $\mathrm{N}$ incorporado ao solo & $0,21 \mathrm{a}$ & $0,24 \mathrm{a}$ & $0,26 \mathrm{a}$ & $0,17 \mathrm{a}$ \\
\hline $\mathrm{N}$ a lanço & $0,16 \mathrm{~b}$ & $0,20 \mathrm{a}$ & $0,18 \mathrm{~b}$ & $0,12 \mathrm{~b}$ \\
\hline \multirow[t]{2}{*}{ C.V. (\%) } & 17,4 & 17,19 & 20,75 & 19,2 \\
\hline & \multicolumn{4}{|c|}{ Leitura SPAD $^{(1)}$} \\
\hline Controle & $55,4 \mathrm{a}$ & $55,9 \mathrm{a}$ & $56,7 \mathrm{a}$ & $56,7 \mathrm{a}$ \\
\hline $\mathrm{N}$ incorporado ao solo & $54,7 \mathrm{a}$ & $55,8 \mathrm{a}$ & $53,9 \mathrm{a}$ & $53,9 \mathrm{a}$ \\
\hline $\mathrm{N}$ a lanço & $52,7 \mathrm{a}$ & $53,1 \mathrm{a}$ & $52,6 \mathrm{a}$ & $52,6 \mathrm{a}$ \\
\hline C.V. (\%) & 15,2 & 11,7 & 12,2 & 15,1 \\
\hline
\end{tabular}

Médias seguidas de mesma letra na coluna não diferem entre si pelo teste de Tukey $(\mathrm{P}>0,05)$. C.V.: coeficiente de variação. ${ }^{(1)}$ Leitura efetuada com medidor portátil de clorofila. Fonte: Elaboração dos autores. 
Entre os métodos de aplicação, houve diferença estatística no florescimento masculino pleno (Vt), R3 e R6, porém, em R2 essa diferença não foi observada entre os métodos de aplicação, provavelmente devido à elevada precipitação pluviométrica ocorrida quando do referido estádio (Figura 1) e a planta estar priorizando outros processos metabólicos neste estádio, inclusive crescimento em altura, conforme observado nas respostas de AP no estádio R2, já discutido.

Para o peso de matéria fresca da parte aérea (MFPA) verificou-se que somente no estádio R2 não houve diferença significativa entre os modos de aplicação, havendo, no entanto, neste estádio diferença significativa entre a aplicação de $\mathrm{N}$ comparativamente ao tratamento controle, sugerindo que a aplicação de $\mathrm{N}$ está diretamente ligada ao aumento de massa verde da planta. Com efeito, ainda que em R2 não houve diferença estatística para o modo de aplicação de N, em termos percentuais, incorporando-se o $\mathrm{N}$ ao solo observou-se um aumento de $13 \%$ na produção de matéria fresca em relação à aplicação a lanço, o que pode ser interessante quando se trata de grandes áreas na região do Cerrado Mato-Grossense. Para esta variável, a incorporação do $\mathrm{N}$ ao solo apresentou diferença estatística positiva nos estádios do pleno florescimento masculino, R3 e R6, apresentando valores superiores ao modo de aplicação a lanço em termos percentuais de $20 \%, 20 \%$ e $27 \%$, respectivamente. Foi comum entre os tratamentos o momento de maior acúmulo de matéria fresca (estádio R3) e onde acontece uma redução da matéria fresca ocasionado principalmente pela perda de água pela planta (estádio R6) (Tabela 1).

Ademais, para a variável peso de matéria seca da parte aérea (MSPA) os resultados seguiram a mesma tendência que para massa fresca, ou seja, não houve diferença significativa entre os métodos de aplicação apenas em R2. No entanto, houve interação apreciável entre o fornecimento ou não de $\mathrm{N}$, conforme observa-se na Tabela 1.

A aplicação de $\mathrm{N}$ conduziu a resultados estatisticamente superiores em todos os estádios quando considera-se os valores de MSPA, o mesmo ocorrendo com Araújo et al. (2003) que obtiveram maior produção de matéria seca com uma dose de ureia ao nível de $180 \mathrm{~kg} \mathrm{ha}^{-1}$. Para o modo de aplicação, somente no estádio vegetativo R2 não houve diferença estatística. De acordo com Carvalho et al. (2007), isso pode ser devido ao fato de que entre os 120-150 dias (variável entre cultivares), a planta de milho atinge a época de máximo acúmulo de matéria seca.

No que se refere à leitura do teor de clorofila (Tabela 1), não houve diferença significativa nos valores observados entre os tratamentos para todos os estádios. Quando compara-se os valores da leitura do teor de clorofila com as variáveis AP, DC, MFPA, MSPA, observa-se que a avaliação do teor de clorofila na folha nos estádios reprodutivos da planta de milho é menos sensível a alterações nutricionais que as demais variáveis analisadas.

A falta de associação entre a leitura SPAD e as demais variáveis analisadas entre os estádios está associada, provavelmente, ao fato das plantas terem apresentado consumo de luxo de $\mathrm{N}$, devido à alta contribuição de $\mathrm{N}$ dos resíduos orgânicos presentes na área relativamente às sucessivas utilizações desta em avaliações experimentais. Bullock \& Anderson (1998) também verificaram baixa correlação entre a leitura correspondente ao teor de clorofila na folha $\mathrm{e}$ rendimento de grãos nos estádios iniciais de desenvolvimento da planta de milho.

Os resultados da produtividade média de grãos da cultura do milho, considerando a aplicação ou não de $\mathrm{N}$ e a forma desta (Tabela 2), demonstraram que a aplicação de $\mathrm{N}$, independentemente do método de aplicação, conduziu a resultados estatisticamente superiores (produtividade 10\% superior, em média) ao tratamento no qual não houve aplicação de N. Apesar do solo da área do experimento ser de textura média e altamente intemperizado (Latossolo de cerrado), este apresentava fertilidade alta, devido aos sucessivos anos de cultivos agrícolas na área, o que justifica a elevada produtividade no controle (sem adubação com $\mathrm{N}$ ). Contudo, esta é uma situação recorrente nas áreas de produção de grãos do cerrado brasileiro.

Tabela 2. Produtividade de grãos, corrigido a umidade para $13 \%$ b.u $\left(\mathrm{kg} \mathrm{ha}^{-1}\right)$ e massa seca de grãos (PMSG) (g) de milho para todos os tratamentos. IFMT - Campus São Vicente, Santo Antônio de Leverger, 2015.

\begin{tabular}{lcc}
\hline $\begin{array}{l}\text { Modo de aplicação } \\
\text { de N }\end{array}$ & Produtividade de grãos & PMSG \\
\hline & $\left(\mathrm{kg} \mathrm{ha}^{-1}\right)$ & $(\mathrm{g})$ \\
Controle & $8.093 \mathrm{~b}$ & $471,4 \mathrm{~b}$ \\
$\mathrm{~N}$ incorporado & $9.734 \mathrm{a}$ & $571,4 \mathrm{a}$ \\
$\mathrm{N}$ a lanço & $8.947 \mathrm{ab}$ & $530,6 \mathrm{ab}$ \\
\hline C.V. $(\%)$ & 8,55 & 8,91 \\
\hline
\end{tabular}

Médias seguidas de mesma letra na coluna, não diferem estatisticamente entre si pelo teste de Tukey $(\mathrm{P}<0,05)$. C.V.: coeficiente de variação. Fonte: Elaboração dos autores.

Resultados semelhantes foram observados por Gomes et al. (2007) avaliando a adubação nitrogenada no milho, em que observaram aumento do rendimento de grãos, do teor de $\mathrm{N}$ nas folhas e da altura de plantas em função do método de aplicação. Isso se explica conforme Karlen et al. (1988) em que a formação de grãos de milho está diretamente relacionada com a translocação de açúcares e de $\mathrm{N}$ na planta, principalmente das folhas. Além disso, folhas bem nutridas em $\mathrm{N}$ têm maior capacidade de assimilação de 
$\mathrm{CO}_{2}$ e de sintetização de carboidratos durante a fotossíntese (BÜLL, 1993).

Ainda observando a variável produtividade, o tratamento no qual o $\mathrm{N}$ foi aplicado incorporando-se ao solo, conquanto não tenha sido observada diferença estatística, apresentou, em média, resultados $8 \%$ superiores ao modo de aplicação a lanço. Resultados semelhantes foram observados por Silva et al. (2005) em que a época e o modo de aplicação do $\mathrm{N}$ influenciaram a produtividade do milho, sendo os melhores resultados obtidos com a incorporação do fertilizante na semeadura ou aos 15 dias após a emergência. Isso deve-se ao fato de que o processo de incorporação de $\mathrm{N}$ ao solo teria condicionado uma maior e mais contínua disponibilidade de $\mathrm{N}$ mineral na solução do solo, provocado maior aproveitamento do $\mathrm{N}$ pelo milho e maior resposta em produtividade de grãos (AMADO et al., 2002).

De modo geral, nas condições do Cerrado MatoGrossense, a adubação nitrogenada de cobertura é aplicada na superfície do solo, pela maior facilidade, tempo e custo da operação; entretanto, as chances de perdas por volatilização de $\mathrm{NH}_{3}$ são aumentadas, pois os restos de cultura promovem a hidrólise rápida do fertilizante e dificultam a retenção da amônia produzida (LARA CABEZAS et al., 1997).

A se analisar os patamares de produtividade de grãos de milho encontrados neste trabalho (Tabela 2), os referidos valores apresentam-se superiores em relação à média nacional, que é de $5.382 \mathrm{~kg} \mathrm{ha}^{-1}$ (CONAB, 2015), estando também acima da média do estado do Mato Grosso, que é de $6.077 \mathrm{~kg} \mathrm{ha}^{-1}$, para a mesma época de cultivo (CONAB, 2015). Isso foi devido ao fato da área experimental utilizada já ter sido utilizada em outros ensaios experimentais e à alta precipitação pluvial ocorrida na região.

Para a variável peso de matéria seca de grãos (PMSG) (Tabela 2), observa-se um comportamento semelhante aos resultados da produtividade, ou seja, o PMSG produzido com o fornecimento de $\mathrm{N}$ foi estatisticamente superior ao tratamento no qual não houve a aplicação e, dentre os modos de aplicação, a aplicação incorporada ao solo, ainda que não estatisticamente superior, conduziu a resultados $8 \%$ superiores.

Quando plotado em um gráfico de correlação de Pearson $\left(\mathrm{R}^{2}\right)$ (Figura 2), a variável produtividade ( $\mathrm{kg}$ ha$\left.{ }^{1}\right)$ como variável dependente e a variável peso de matéria seca de grãos (g) como variável independente, observou-se uma alta correlação entre estas $\left(R^{2}=0,99\right)$ em todos os tratamentos, significando que o maior acúmulo de matéria seca de grãos tende a proporcionar maiores produtividades na cultura do milho. Portanto, conforme os resultados apresentados na Figura 2, em que pese a não diferenciação estatística para produtividade entre os métodos de aplicação, aquele tratamento onde a aplicação de $\mathrm{N}$ foi feita incorporandose ao solo obteve um acúmulo de matéria seca nos grãos $8 \%$ superior àquele tratamento em que o $\mathrm{N}$ foi fornecido a lanço; por sua vez, esse ganho de $8 \%$ de matéria seca de grãos culminou por proporcionar maior produtividade (Figura 2), por serem variáveis diretamente correlacionadas.

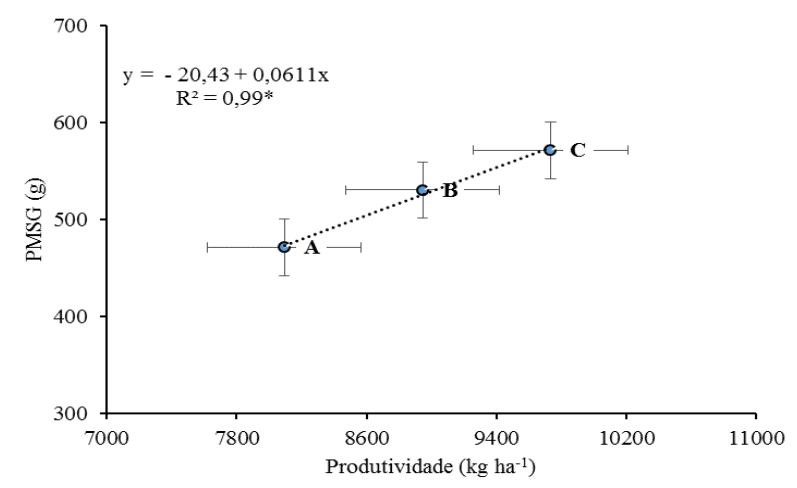

Figura 2. Correlação entre os valores de massa seca de grãos (MSG) e a produtividade de grãos de milho $\left(\mathrm{kg} \mathrm{ha}^{-1}\right)$ sendo A: tratamento sem a aplicação de N; B: tratamento com o N aplicado a lanço; $\mathrm{C}$ : tratamento com o $\mathrm{N}$ aplicado incorporando-se ao solo. IFMT - Campus São Vicente, Santo Antônio de Leverger, 2015. *Significativo ao nível de $1 \%$ de probabilidade. Fonte: Elaboração dos autores.

Estes resultados concordam com Costa et al. (2012) que, estudando a adubação nitrogenada no consórcio de milho com duas espécies de braquiária em sistema plantio direto, verificaram que os componentes da produção e a produtividade de grãos apresentaram efeito das doses de N em cobertura. Segundo esses autores, os componentes número de fileiras, grãos por fileira e grãos por espiga, estão diretamente associados e apresentaram o mesmo comportamento linear crescente em função da aplicação de $\mathrm{N}$ em cobertura, o que mostra o papel fundamental deste nutriente para a formação dos grãos de milho na espiga. Esses resultados evidenciam a importância do $\mathrm{N}$, tanto no que se refere ao estado nutricional da planta quanto à sua influência positiva no aumento do número e da massa de grãos de milho, proporcionando maior produtividade de grãos.

\section{Conclusão}

$\mathrm{O}$ método de aplicação de $\mathrm{N}$ não afetou significativamente a produtividade de grãos do milho. Apesar disso, a produtividade do milho alcançada com a aplicação do $\mathrm{N}$ incorporado ao solo foi $10 \%$ superior à produtividade alcançada quando se aplicou o $\mathrm{N}$ a lanço. Logo, a escolha do melhor método de se aplicar o $\mathrm{N}$ deverá ser baseada no custo benefício de incorporar o fertilizante e o aumento de produtividade esperado, levando-se em conta a dinâmica operacional do sistema. 


\section{Referências}

ALVES, V. M. C.; VASCONCELlOS, A. A.; FREIRE, F. M.; PITTA, G. V. E.; FRANÇA, G. E.; FILHO, A. R.; ARAÚJO, J. M.; VIEIRA, J. R.; LOUREIRO, J. E. Milho. In: RIBEIRO, A. C.; GUIMARÃES, P. T. G.; VENEGAS, V. H. A. (Eds.). Recomendações para o uso de corretivos e fertilizantes em Minas Gerais. Viçosa: Comissão de Fertilidade do Solo do Estado de Minas Gerais, 1999. p. 314316.

AMADO, T. J. C.; MIELNICZUK, J.; AITA, C. Recomendação de adubação nitrogenada para o milho no RS e SC adaptada ao uso de culturas de cobertura do solo, sob sistema plantio direto. Revista Brasileira de Ciência do Solo, Viçosa-MG, v. 26, n. 1, p. 241-248, 2002.

ARGENTA, G.; SILVA, P. D.; BORTOLINI, C. G.; FORSTHOFER, E. L.; STRIEDER, M. L. Relação da leitura do clorofilômetro com os teores de clorofila extraível e de nitrogênio na folha de milho. Revista Brasileira de Fisiologia Vegetal, Campinas-SP, v. 13, n. 2, p. 158-167, 2001.

BÜLL, L.T. Nutrição mineral do milho. In: BÜLL, L.T.; CANTARELLA, H. (Eds.) Cultura do milho: fatores que afetam a produtividade. Piracicaba-SP: Potafós, 1993. p. 63146.

BULLOCK, D. G.; ANDERSON, D. S. Evaluation of the Minolta SPAD 502 chlorophyll meter for nitrogen management in corn. Journal of Plant Nutrition, New York, v. 21, n. 4 , p. $741-755,1998$.

CANTARELLA, H.; MARCELINO, R. Fontes alternativas de nitrogênio para a cultura do milho. Informações Agronômicas, v. s/n, n. 122, p. 12-14, 2008.

CARVALHO, I. R.; DE SOUZA, V. Q.; FOLLMANN, D. N.; NARDINO, M.; SCHMIDT, D.; WESTPHALEN, F.; WESTPHALEN, F. Desempenho agronômico de híbridos de milho em ambiente irrigado e sequeiro. Enciclopédia Biosfera, Goiânia-GO, v. 10, n. 18, p. 1144-1153, 2014.

CARVALHO, L. B.; BIANCO, S.; PITELLI, R. A.; BIANCO, M. S. Estudo comparativo do acúmulo de massa seca e macronutrientes por plantas de milho var. BR-106 e Brachiaria plantaginea. Planta Daninha, Viçosa-MG, v. 25, n. 2, p. 293-301, 2007.

COELHO, A. M. Nutrição e adubação do milho. In: CRUZ, J. C.; KARAM, D.; MONTEIRO, M. A. R.; MAGALHÃES, P. C. (Eds.) A cultura do milho. Sete Lagoas-MG: Embrapa Milho e Sorgo, 2008. cap. 6, p. 131-157.

CONAB. COMPANHIA NACIONAL DE ABASTECIMENTO. Acompanhamento da safra brasileira de grãos. 8 ed. Brasília: Conab, 2015.

COSTA, N. R.; ANDREOTTI, M.; GAMEIRO, R. A.; PARIZ, C. M.; BUZETTI, S.; LOPES, K S. M. Adubação nitrogenada no consórcio de milho com duas espécies de braquiária em sistema plantio direto. Pesquisa Agropecuária Brasileira, Brasília-DF, v.47, n. 9, p. 1038-1047, 2012.
EMBRAPA. EMPRESA BRASILEIRA DE PESQUISA AGROPECUÁRIA. Sistema de produção. Sete Lagoas: Embrapa, 2006. 225p.

FERRARA, R. M.; LOUBET, B.; DECUQ, C.; PALUMBO, A. D.; DI TOMMASIC, P.; MAGLIULO, V.; MASSON, S.; PERSONNE, E.; CELLIER, P.; RANA, G. Ammonia volatilisation following urea fertilisation in an irrigated sorghum crop in Italy. Agricultural and Forest Meteorology, Connecticut, v. 195, n. 1, p. 195-196, 2014.

FONTOURA, S. M. V.; BAYER, C. Ammonia volatilization in no-till system in the south-central region of the State of Paraná, Brazil. Revista Brasileira de Ciência do Solo, Viçosa-MG, v. 34, n. 5, p. 1677-1684, 2010.

GOMES, R. F.; SILVA, A. G.; ASSIS, L.; PIRES, F. R. Efeito de doses e da época de aplicação de nitrogênio nos caracteres agronômicos da cultura do milho sob plantio direto. Revista Brasileira de Ciência do Solo, Viçosa-MG, v. 31, n. 5, p. 931-938, 2007.

KARLEN, D. L.; FLANNERY, R. L.; SADLER, E. J. Aerial accumulation and partitioning of nutrients by corn. Agronomy Journal, Madison-WI, v. 80, n. 2, p. 232-242, 1988.

LARA CABEZAS, W. A. R.; KORNDORFER, G. H.; MOTTA, S. A. Volatilização de N-NH3 na cultura de milho: II. Avaliação de fontes sólidas e fluidas em sistema de plantio direto e convencional. Revista Brasileira de Ciência do Solo, v. 21, n. 3, p. 489-496, 1997.

OLIVEIRA, O. J.; SIQUEIRA, J. L.; SANTOS, V. S. Classificação climática da região de São Vicente da Serra segundo critérios de W.W. Köeppen e critérios de W.C. Thornthwaite. Cuiabá: CEFET de Cuiabá, 2004. 24p. (Boletim Técnico, 1)

SANTOS, H. P.; PEREIRA, L. R. Efeito de sistemas de sucessão de cultura de inverno sobre algumas características agronômicas de milho em plantio direto. Revista Brasileira de Ciência do Solo, Viçosa, v. 29, n. 4, p. 1691-1694, 1994

SILVA, E.C.; BUZETTI, S.; GUIMARÃES, G.L.; LAZARINI, E.; SÁ, M.E. Doses e épocas de aplicação de nitrogênio na cultura do milho em plantio direto sobre Latossolo vermelho. Revista Brasileira de Ciência do Solo, Viçosa-MG, v. 29, p. 353-362, 2005.

SOUZA, J. A.; BUZETTI, S.; TEIXEIRA FILHO, M. C. M.; ANDREOTTI, M.; SÁ, M. D.; ARF, O. Adubação nitrogenada na cultura do milho safrinha irrigado em plantio direto. Bragantia, Piracicaba-SP, v. 70 , n. 2, p. 447-454, 2011.

TOZETTI, A. D.; BILLIA, R. C.; SILVA, C.; CERVIGNI, G.; GOMES, O. M. T. Avaliação de progênies de milho na presença e ausência de adubo. Revista Científica Eletrônica de Agronomia, Garça-SP, v. 6, n. 5, p. 6-10, 2004.

VARVEL, G. E.; SCHPERS, J. S.; FRANCIS, D. D. Ability for in-season correction of nitrogen deficiency in corn using chlorophyll meters. Soil Science Society of America Journal, Madison-WI, v. 61, n. 4, p. 1233-1239, 1997. 